\title{
Peertechz
}

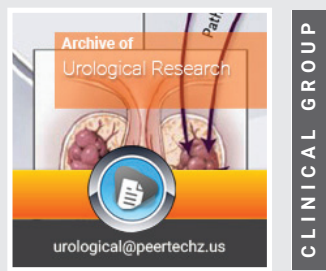

\section{The influence of COVID-19 restrictions on bladder and bowel symptoms: A Case Report}

Received: 19 July, 2021

Accepted: 09 August, 2021

Published: 10 August, 2021

*Corresponding authors: Marie Nativ, Department of Neuro-Urology, Rambam Hospital, David Pinski Street 36, Haifa, Israel, Tel: +972 56628336;

E-mail: Nativ.marie@gmail.com

Keywords: COVID-19; Urinary disorders; Bowel disorders; Pelvic floor; Quality of life

https://www.peertechzpublications.com

\section{Check for updates}

\section{Marie Nativ*, Boaz Appel, Valentin Shabataev, Alexander Greenstein and Ilan Gruenwald}

Department of Neuro-Urology, Rambam Hospital, Haifa, Israel

\begin{abstract}
Background: The COVID-19 pandemic has undoubtedly affected millions around the globe. The infection and the restrictions applied to eradicate it carry with them physical and mental consequences related to stress and change of daily habits.

In our case report, we describe the effect of COVID-19 lockdowns on urinary and bowel symptoms, as well as the mental health.

Our patient was followed during a period of three lockdowns. Urinary and bowel symptoms as well as mental health were reported by a pelvic floor physiotherapist, using validated questionnaires, throughout lockdown and non-lockdown periods.
\end{abstract}

Results: Our results show that during lockdown periods, there is a transient decrease in patient's quality of life, which improved in the non-lockdown periods.

Conclusion: COVID-19 restrictions alter patient's physical and mental health, indirectly related to the viral infection. Many patients may suffer from worsening urinary, bowel and mental symptoms that may need closer surveillance during lockdown periods. Healthcare workers should emphasize the importance of keeping a routine during lockdown periods and preventive measures should be taken in the form of home exercises instructions and phone follow up.

\section{Introduction}

Since the COVID-19 pandemic outbreak at the beginning of 2020, restrictions were applied in many countries in order to decrease the infection rate among the general population. Some of these restrictions included lockdown periods, where people were prevented from leaving their houses for several days. These measures had a major influence on people's daily routine, lifestyle, dietary habits and mental health [1-5]. Several studies have found that lack of physical activity and sedentary lifestyle were linked to increased risk of developing Lower Urinary Tract Symptoms (LUTS) and bowel dysfunction $[6,7]$. Moreover, some studies have demonstrated a direct correlation between such sedentary lifestyle and depression [8] which together with anxiety are known risk factors for developing LUTS [9] or bowel dysfunction [10,11].
Hereby we report a follow-up of a patient from our pelvic floor clinic who suffered from intermittent bladder and bowel symptoms throughout three COVID-19 lockdown period.

\section{Material and methods - Case presentation}

Our case presentation focuses on a 69-year-old divorced woman with G3P3 who was referred to our Functional Urology clinic for assessment of both bladder and bowel symptoms that started at the beginning of the COVID-19 pandemic outbreak.

We report her symptoms from March 2020 to March 2021, throughout 3 lockdown periods.

\section{Patient assessment}

The patient is healthy and does not suffer from any 
systemic medical conditions. Her surgical history includes a hysterectomy in 2003 due to a large uterine fibroid.

After a first lockdown period lasting 24 days, the patient was first evaluated in our clinic. The patient lives alone and she mentions decreased physical activity, and changes in her diet and mood during the past month.

Her laboratory tests, including basic metabolic panel, complete blood count, urine culture and urinalysis, were all within normal range. The patient's symptoms started during the first lockdown, presenting mostly with severe nocturia (4 times a night) and for a lesser extent: frequency, urgency and urge incontinence. The patient reported having daily bowel movements, sometimes several times a day in small amounts, not at a regular time. The consistency of her stool was graded BRISTOL 4-5. On physical examination, the patient was overweight (BMI 31.5). A thorough pelvic floor examination demonstrated weak pelvic floor muscles (PERFECT 2/2/7) without any trigger points, a grade 1 cystocele and a grade 1 rectocele.

At that point, the patient started pelvic floor physiotherapy with a certified pelvic floor physiotherapist, using a combination of techniques to improve her symptoms, including pelvic floor muscle exercises with biofeedback and electrical stimulation, behavioral modifications and bladder and bowel training techniques, as well as lifestyle modifications including: dietary modifications and daily physical activity. The patient was recommended to fill up a bladder diary for future evaluation.

During the second lockdown, which lasted for 21 days the patient reported worsening of her urinary symptoms with the addition of pain near the external anal sphincter when upon effort, fecal urgency and episodes of fecal incontinence on a weekly basis. At the end of the lockdown, the patient resumed pelvic floor physiotherapy treatment. She presented a bladder diary (Table 1 ) that demonstrated urinary frequency every 2 hours associated with urgency, and 2 or 3 urinations within a short time from each other, explained by the patient as incomplete urination. Few episodes of urge incontinence were noticed. Nocturia occurred 3 or 4 times per night with some nights increasing up to 7 or 8 times. The patient mentioned using 2 thick pads a day and 1 thick pad at night.

Similarly, after the third lockdown period, which lasted for one month, the patient reported worsening of her symptoms and resumed physiotherapy.

Table 1: Two days bladder diary during the second lockdown period, before starting pelvic floor physiotherapy treatment:

\begin{tabular}{|c|c|c|c|c|c|c|c|c|c|c|c|}
\hline Hours & Drink & $\begin{array}{l}\text { Urine } \\
\text { S/M/L }\end{array}$ & Urgency & Leakage & Comments & Hours & Drink & \begin{tabular}{l|} 
Urine \\
S/M/L
\end{tabular} & Urgency & Leakage & Comments \\
\hline 09:30 & & M & 9 & Yes & $\begin{array}{c}\text { On the way to the toilet- } \\
\text { change pad }\end{array}$ & $9: 45$ & & L & 9 & yes & On the way to the toilet-change pad \\
\hline 10:00 & Hot Chocolate & S & 6 & & & $10: 00$ & & S & 4 & & \\
\hline $10: 15$ & & & & & $\begin{array}{l}\text { Bowel movement } \\
\text { urgency } 9\end{array}$ & $10: 15$ & Hot Chocolate & & & & \\
\hline $11: 30$ & & M & 9 & $\begin{array}{l}\text { Yes- } \\
\text { drops }\end{array}$ & & $12: 10$ & Glass of water & & & & \\
\hline $12: 00$ & Glass of water & S & 5 & & & $13: 00$ & Glass of water & & & & \\
\hline $14: 00$ & Glass of water & $M$ & 8 & & & $14: 00$ & & M & 8 & & \\
\hline $14: 10$ & & S & 3 & & Bowel Movement & $14: 30$ & $\begin{array}{c}\text { Glass of water } \\
\text { lunch }\end{array}$ & S & 3 & & \\
\hline $14: 15$ & $\begin{array}{c}\text { Glass of water } \\
\text { lunch }\end{array}$ & & & & & $17: 45$ & & L & 9 & yes & $\begin{array}{c}\text { On the way to the toilet-change pad } \\
\text { during trip outside }\end{array}$ \\
\hline $15: 00$ & & L & 7 & Yes & $\begin{array}{c}\text { On the way to the toilet- } \\
\text { change pad }\end{array}$ & $18: 30$ & & & & & Bowel movement urgency 10 \\
\hline 16:00 & Glass of water & M & 6 & & & 19:30 & & M & 8 & yes & $\begin{array}{l}\text { When opening the door to come } \\
\text { home }\end{array}$ \\
\hline $17: 45$ & & S & 3 & & & $20: 15$ & & S & 4 & & \\
\hline 18:00 & & M & 9 & $\begin{array}{l}\text { Yes- } \\
\text { drops }\end{array}$ & & 22:00 & $\begin{array}{c}\text { Glass of water } \\
\text { Dinner }\end{array}$ & & & & \\
\hline $20: 15$ & $\begin{array}{c}\text { Glass of water } \\
\text { Dinner }\end{array}$ & & & & & $22: 30$ & & & & & \\
\hline $21: 15$ & Glass of water & M & 8 & Yes & $\begin{array}{c}\text { On the way to the toilet- } \\
\text { change pad }\end{array}$ & $22: 45$ & $\begin{array}{l}\text { Chocolates/ } \\
\text { Sweets }\end{array}$ & M & 8 & yes & On the way to the toilet-change pad \\
\hline $22: 30$ & $\begin{array}{l}\text { Chocolates/ } \\
\text { Sweets }\end{array}$ & $S$ & 6 & & & 23:00 & Glass of water & $S$ & 3 & & \\
\hline $23: 15$ & & S & 6 & & & 23:30 & & S & 4 & & Before sleeping \\
\hline 00:00 & & $\mathrm{S}$ & & & Before Sleeping & $2: 30$ & & M & 6 & & \\
\hline $02: 30$ & & M & 5 & & & $3: 30$ & & S & 8 & & \\
\hline $5: 00$ & & $M$ & 9 & & & $7: 00$ & & $\mathrm{~L}$ & 9 & Yes & \\
\hline $7: 00$ & & M & 9 & Yes & & $7: 30$ & & S & 3 & & \\
\hline $7: 20$ & & S & 5 & & & & & & & & \\
\hline
\end{tabular}

Citation: Nativ M, Appel B, Shabataev V, Greenstein A, Gruenwald I (2021) The influence of COVID-19 restrictions on bladder and bowel symptoms: A Case Report. Arch Urol Res 5(2): 030-034. DOI: https://dx.doi.org/10.17352/aur.000035 
The patient was instructed to fill up symptom severity surveys during and after each lockdown period. These questionnaires include: the Incontinence Severity Index (ISI) for urinary symptoms, Wexner and Vaizey Score for fecal symptoms and the Generalized Anxiety Disorder 7 items (GAD7) (Figure 1).

\section{Results}

The patient was first evaluated after the first lockdown period and followed during 2 lockdown periods and 3 post lockdown periods.

The patient's presenting symptoms included urinary frequency, urgency, urge incontinence and nocturia from the first lockdown period. She scored 6/12 on the ICIQ 0/24 on the Wexner and Vaizey Score and 5/21 on the GAD-7. After physiotherapy treatment, her symptoms improved scoring 5/12 on the ICIQ and 4/21 on the GAD-7.

During the second lockdown period, her symptoms worsen and she started suffering from fecal urgency and fecal urge incontinence, scoring then $12 / 12$ on the ICIQ $12 / 24$ on the Wexner and Vaizey Score and 7/21 on the GAD-7. After the patient continued pelvic floor physiotherapy in the post lockdown period, she improved in all aspects scoring $1 / 12$ on the ICIQ 2/24 on the Wexner and Vaizey Score and 3/21 on the GAD-7.

During the third lockdown period, the patient mentioned trying to keep exercising at home and to follow all the instructions she received during treatment, but had difficulties while being restricted at home. By the end of the lockdown, her symptoms again increased in severity: 12/12 on the ICIQ 14/24 on the Wexner and Vaizey Score and 10/21 on the GAD-7.

Similarly to the previous post lockdown periods, after 6 weeks of pelvic floor physiotherapy treatment, the patient reported complete resolution of her urinary and fecal symptoms. She used a thin pad as a preventive measure, during the day and none at night and at the same time her mental state was greatly improved: she scored $0 / 12$ on the ICIQ $0 / 24$ on the Wexner and Vaizey Score and 2/21 on the GAD-7.

\section{Discussion}

With more than 2 million confirmed deaths worldwide during the COVID-19 outbreak in 2020, it might seem that these tragic numbers are just the tip of the iceberg with respect to many overlooked and unreported morbidities. The COVID 19 outbreak and protective measures taken for disease eradication may have an impact on social, economic, psychological, and physical wellbeing of people [12]. Being confined at home under social isolation during a lockdown period may have a major negative impact on an individual's mental-health status and could be a risk factor for developing mental-health related disorders [5]. Similarly, the change in routine can lead to a decline in the general wellbeing affecting diet, sleeping habits and the amount of physical activity [3, 4,13,14].

It was proven that LUTS strongly correlate with a healthy and active lifestyle [6]. Urinary urgency and urinary incontinence are associated with sedentary behavior in older women $[15,16]$ and functional bowel disorders such as constipation, fecal incontinence or fecal urgency, are associated with improper dietary habits or sleep hygiene, lack of physical activity, and mental disorders $[17,18]$. Since physical activity, sleep, diet and mood were all affected during the COVID-19 lockdown periods [12-14], it is not surprising to see a correlation between bladder and bowel disorders and lockdown periods during the COVID-19 outbreak.

In our case report, the patient reported worsening of her

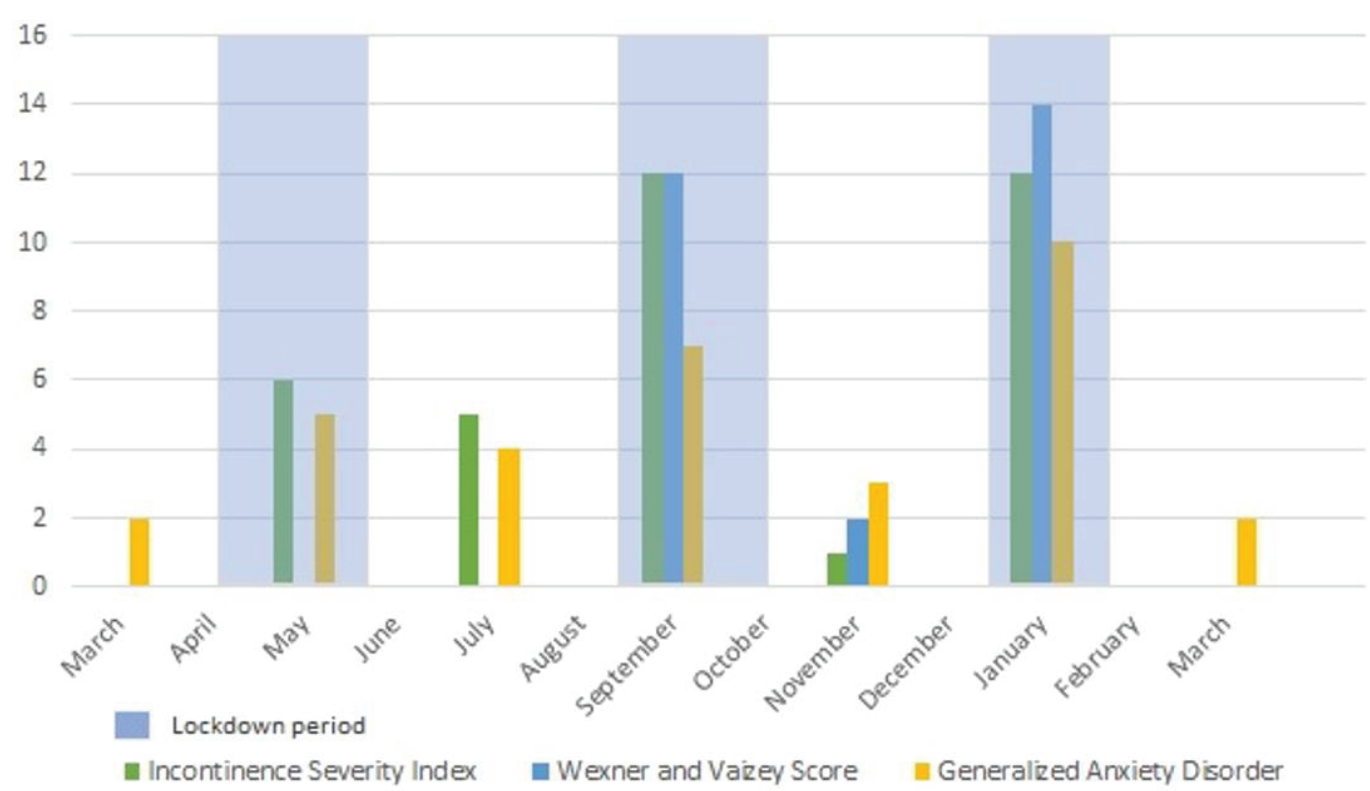

Figure 1: Severity of the patient's urinary symptoms using the Incontinence Severity Index (ISI), fecal symptoms using the Wexner and vaizey Score and anxiety levels with the Generalized Anxiety disorder 7 items (GAD-7), reported before, during and after lockdown periods.

Citation: Nativ M, Appel B, Shabataev V, Greenstein A, Gruenwald I (2021) The influence of CoVID-19 restrictions on bladder and bowel symptoms: A Case Report. Arch Urol Res 5(2): 030-034. DOI: https://dx.doi.org/10.17352/aur.000035 
urinary and fecal symptoms during each lockdown period, while at the same time suffering from a decrease in quality of life and healthy life style (Figure 1). Similar to our findings, in a cross-sectional study of more than 20,000 women Felde et $\mathrm{al}^{\prime}$ showed that anxiety and depression are associated factors with urinary incontinence and that the severity of those conditions correlated with the urinary incontinence severity [19].

As presented in Figure 1, the improvement in urinary and bowel symptoms correlates with each period without lockdown, this fact supports our hypothesis that while lockdowns aid in decreasing viral infection they come with the risk of affecting other health-related conditions.

Based on these findings, we have created a treatment plan during the COVID-19 periods (lockdown and off lockdown) in order to focus on restoring a healthy and regular daily routine, using behavioral retraining along with physical therapy $[20,21]$. Restoring proper habits when being confined at home is a challenging task which requires enforcing regular bedtime and wake-up time, scheduling meals or programming daily activities, especially when socially distancing, missing work routine and missing the possibilities of outdoor activities.

As shown in our case, the combination of regular sessions with a pelvic floor physiotherapist, daily home pelvic floor exercises program, breathing exercises, daily physical activity and behavioral modifications (including dietary changes and sleep hygiene) contributed to decrease her LUTS and bowel dysfunctions, as well as her anxiety level.

Similar to other women, this patient suffered from risk factors for developing urinary incontinence: advanced age, multiple pregnancies and poor diet and physical activity. However, the sudden onset and fluctuation of symptoms around lockdown periods imply that the symptoms were related to other factors such as pandemic lockdown related changes in anxiety and lifestyle [22].

\section{Conclusion}

This case report demonstrates the correlation between improvement and aggravation of urinary and bowel functions in relation to COVID-19 restrictions. This case unmasks a major concern of overlooked urinary, fecal and mental wellbeing related disorder that are related to restriction measures taken during the COVID-19 outbreak.

Care givers should be more proactive during these periods to follow up patients, offer online telemedicine sessions and provide physical and mental tools for keeping a healthy everyday routine.

\section{Declarations}

Informed consent: Written informed consent was obtained from the patient(s) for their anonymized information to be published in this article.

Contributorship: MN managed the patient's treatment, data collection and writing of the review, BA and AG helped in data collection, VS was involved in questionnaires assessment, IG helped in gathering data and writing the review.

\section{References}

1. Ullah M, Wahab A, Saeed S, Khan SU, Ali H, et al. (2021) Coronavirus and its terrifying inning around the globe: The pharmaceutical cares at the main frontline. Chemosphere 275: 129968. Link: https://bit.ly/3fKyh4i

2. Hu Z, Lin X, Chiwanda Kaminga A, Xu H (2020) Impact of the COVID-19 Epidemic on Lifestyle Behaviors and Their Association With Subjective WellBeing Among the General Population in Mainland China: Cross-Sectional Study. J Med Internet Res 22: e21176. Link: https://bit.ly/3ivFJBN

3. Górnicka M, Drywień ME, Zielinska MA, Hamułka J (2020) Dietary and Lifestyle Changes During COVID-19 and the Subsequent Lockdowns among Polish Adults: A Cross-Sectional Online Survey PLifeCOVID-19 Study. Nutrients 12: 2324. Link: https://bit.ly/3fNURsu

4. Di Renzo L, Gualtieri P, Pivari F, Soldati L, Attinà A, et al. (2020) Eating habits and lifestyle changes during COVID-19 lockdown: an Italian survey. J Transl Med 18: 229. Link: https://bit.ly/3xxR6h1

5. Torales J, O'Higgins M, Castaldelli-Maia JM, Ventriglio A (2020) The outbreak of COVID-19 coronavirus and its impact on global mental health. Int $\mathrm{J}$ Soc Psychiatry 66: 317-320. Link: https://bit.ly/3jBvPOs

6. Steenstrup B, Le Rumeur E, Moreau S, Cornu JN (2018) Sedentary lifestyle and urinary incontinence in women: A literature review. Prog Urol 28: 973-979. Link: https://bit.ly/2U2dAsH

7. Asakura K, Masayasu S, Sasaki S (2017) Dietary intake, physical activity, and time management are associated with constipation in preschool children in Japan. Asia Pac J Clin Nutr 26: 118-129. Link: https://bit.ly/3IPSpWj

8. Zhai L, Zhang Y, Zhang D (2015) Sedentary behaviour and the risk of depression: a meta-analysis. $\mathrm{Br} \mathrm{J}$ Sports Med 49: 705-709. Link: https://bit.ly/3ILljqD

9. Huang $\mathrm{CL}$, Wu MP, Ho CH, Wang JJ (2017) The bidirectional relationship between anxiety, depression, and lower urinary track symptoms: A nationwide population-based cohort study. J Psychosom Res 100: 77-82. Link: https://bit.ly/3iDuYxH

10. Hosseinzadeh ST, Poorsaadati S, Radkani B, Forootan M (2011) Psychological disorders in patients with chronic constipation. Gastroenterology Hepatol Bed Bench 4: 159-163. Link: https://bit.ly/37sBD7h

11. Lydiard RB (2001) Irritable bowel syndrome, anxiety, and depression: what are the links?. J Clin Psychiatry 62: 38-47. Link: https://bit.ly/2WZnFYv

12. Kaczorowski J, Del Grande C (2021) Beyond the tip of the iceberg: direct and indirect effects of COVID-19. Lancet Digit Health 3: e205-e206. Link: https://bit.ly/3jFXjCq

13. Gualano MR, Lo Moro G, Voglino G, Bert F, Siliquini R (2020) Effects of Covid-19 Lockdown on Mental Health and Sleep Disturbances in Italy. Int J Environ Res Public Health. 17: 4779. Link: https://bit.ly/3IJ4s7V

14. Robinson E, Boyland E, Chisholm A, Harrold J, Maloney NG, et al. (2021) Obesity, eating behavior and physical activity during COVID-19 lockdown: A study of UK adults. Appetite 156: 104853. Link: https://bit.ly/3AqCXE9

15. Jerez-Roig J, Booth J, Skelton DA, Giné-Garriga M, Chastin S, et al. (2020) Is urinary incontinence associated with sedentary behaviour in older women? Analysis of data from the National Health and Nutrition Examination Survey. PloS One 15: e0227195. Link: https://bit.ly/3IKmEhm

16. Farrés-Godayol P, Jerez-Roig J, Minobes-Molina E, Yildirim M, Goutan-Roura $E$, et al. (2021) Urinary incontinence and sedentary behaviour in nursing home residents in Osona, Catalonia: protocol for the OsoNaH project, a multicentre observational study. BMJ Open 11: e041152. Link: https://bit.ly/3AkA4Ve

Citation: Nativ M, Appel B, Shabataev V, Greenstein A, Gruenwald I (2021) The influence of COVID-19 restrictions on bladder and bowel symptoms: A Case Report. Arch Urol Res 5(2): 030-034. DOI: https://dx.doi.org/10.17352/aur.000035 
17. Swanson GR, Burgess HJ (2017) Sleep and Circadian Hygiene and Inflammatory Bowel Disease. Gastroenterol Clin North Am 46: 881-893. Link: https://bit.ly/3sakhph

18. Werth BL, Christopher SA (2021) Potential risk factors for constipation in the community. World J Gastroenterol 27: 2795-2817. Link: https://bit.ly/2U1yXdG

19. Felde G, Engeland A, Hunskaar S (2020) Urinary incontinence associated with anxiety and depression: the impact of psychotropic drugs in a cross-sectional study from the Norwegian HUNT study. BMC Psychiatry 20: 521.Link: https://bit.ly/3xszaUY
20. Scott KM (2014) Pelvic floor rehabilitation in the treatment of fecal incontinence. Clin Colon Rectal Surg 27: 99-105. Link: https://bit.ly/3AmLPdW

21. Milne JL (2008) Behavioral therapies for overactive bladder: making sense of the evidence. Journal of Wound, Ostomy Continence Nursing : Official Publication of the Wound, Ostomy and Continence Nurses Society 35: 93103. Link: https://bit.ly/2U2cKfx

22. Hassani D, Arya L, Andy U (2020) Continence: Bowel and Bladder and Physical Function Decline in Women. Curr Geriatr Rep 9: 64-71. Link: https://bit.ly/3jBuqaE
Discover a bigger Impact and Visibility of your article publication with

Peertechz Publications

Highlights

* Signatory publisher of ORCID

* Signatory Publisher of DORA (San Francisco Declaration on Research Assessment)

* Articles archived in worlds' renowned service providers such as Portico, CNKI, AGRIS, TDNet, Base (Bielefeld University Library), CrossRef, Scilit, J-Gate etc.

* Journals indexed in ICMJE, SHERPA/ROMEO, Google Scholar etc.

- OAI-PMH (Open Archives Initiative Protocol for Metadata Harvesting)

* Dedicated Editorial Board for every journal

* Accurate and rapid peer-review process

* Increased citations of published articles through promotions

* Reduced timeline for article publication

Submit your articles and experience a new surge in publication services (https://www.peertechz.com/submission).

Peertechz journals wishes everlasting success in your every endeavours.

Copyright: @ 2021 Nativ M, et al. This is an open-access article distributed under the terms of the Creative Commons Attribution License, which permits unrestricted use distribution, and reproduction in any medium, provided the original author and source are credited. 